\title{
Characterization of Surrogate Molten Salt Reactor Aerosol Streams
}

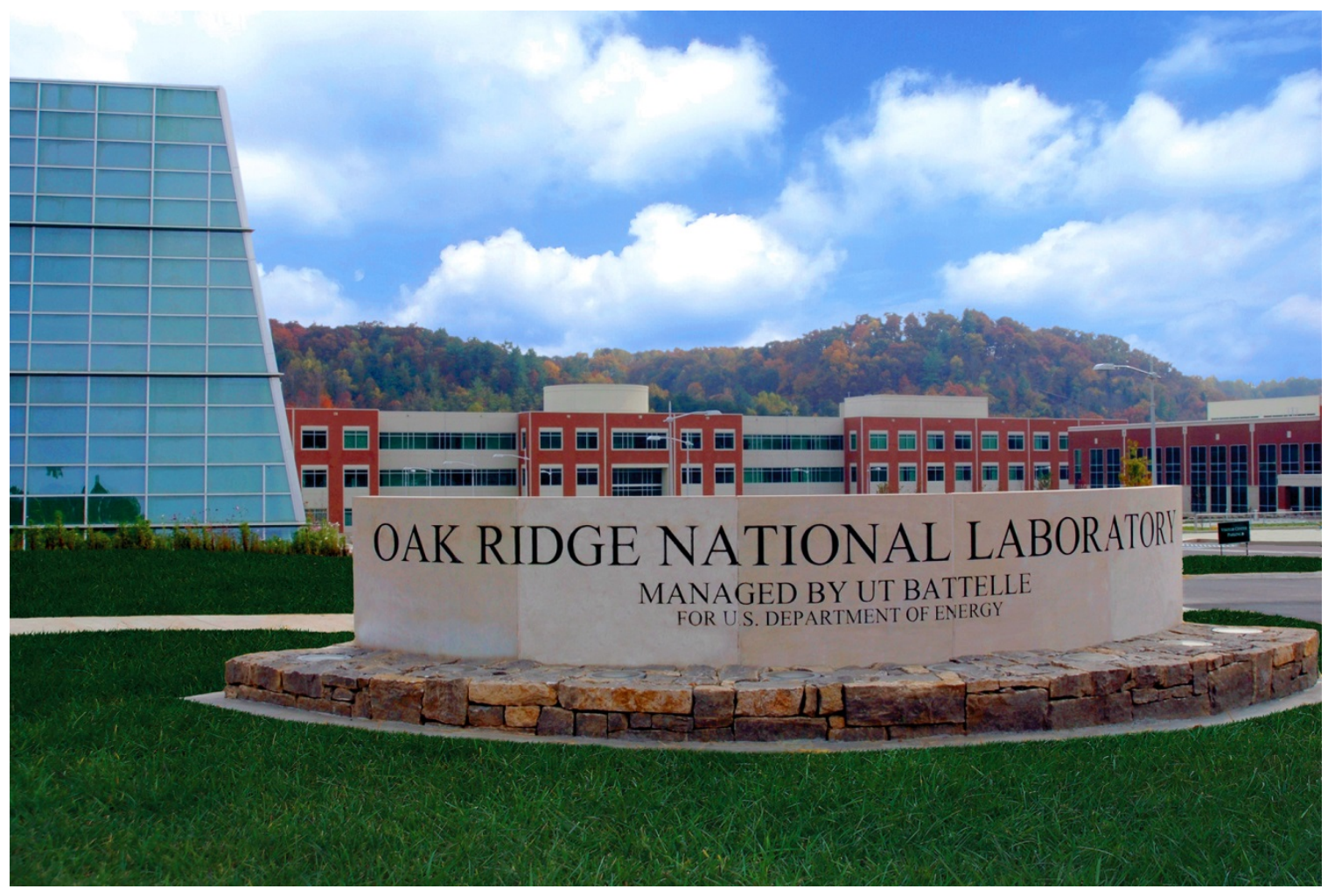

H. Andrews

J. McFarlane

September 2021 


\title{
DOCUMENT AVAILABILITY
}

Reports produced after January 1, 1996, are generally available free via US Department of Energy (DOE) SciTech Connect.

Website www.osti.gov

Reports produced before January 1, 1996, may be purchased by members of the public from the following source:

\author{
National Technical Information Service \\ 5285 Port Royal Road \\ Springfield, VA 22161 \\ Telephone 703-605-6000 (1-800-553-6847) \\ TDD 703-487-4639 \\ Fax 703-605-6900 \\ E-mail info@ntis.gov \\ Website http://classic.ntis.gov/
}

Reports are available to DOE employees, DOE contractors, Energy Technology Data Exchange representatives, and International Nuclear Information System representatives from the following source:

Office of Scientific and Technical Information

PO Box 62

Oak Ridge, TN 37831

Telephone 865-576-8401

Fax 865-576-5728

E-mail reports@osti.gov

Website https://www.osti.gov/

This report was prepared as an account of work sponsored by an agency of the United States Government. Neither the United States Government nor any agency thereof, nor any of their employees, makes any warranty, express or implied, or assumes any legal liability or responsibility for the accuracy, completeness, or usefulness of any information, apparatus, product, or process disclosed, or represents that its use would not infringe privately owned rights. Reference herein to any specific commercial product, process, or service by trade name, trademark, manufacturer, or otherwise, does not necessarily constitute or imply its endorsement, recommendation, or favoring by the United States Government or any agency thereof. The views and opinions of authors expressed herein do not necessarily state or reflect those of the United States Government or any agency thereof. 
Radioisotope Science and Technology Division

\section{CHARACTERIZATION OF SURROGATE MOLTEN SALT REACTOR AEROSOL STREAMS}

H. Andrews

J. McFarlane

September 2021

Prepared by OAK RIDGE NATIONAL LABORATORY

Oak Ridge, TN 37831-6283

managed by

UT-BATTELLE LLC

for the

US DEPARTMENT OF ENERGY

under contract DE-AC05-00OR22725 



\section{CONTENTS}

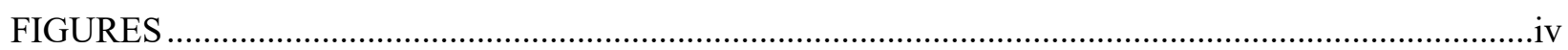

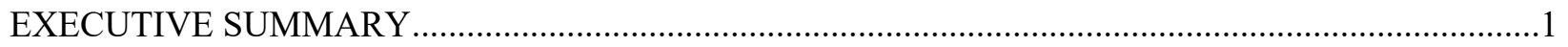

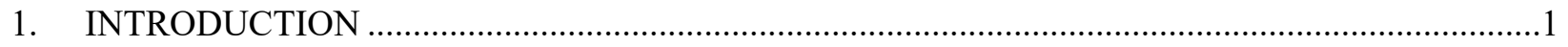

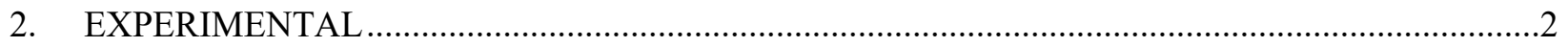

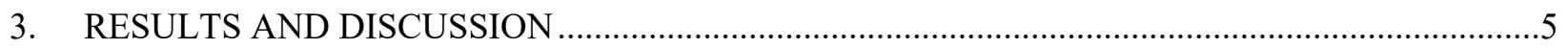

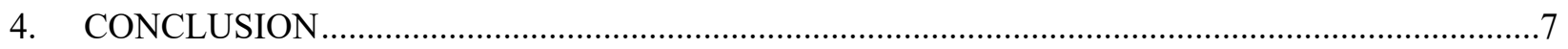

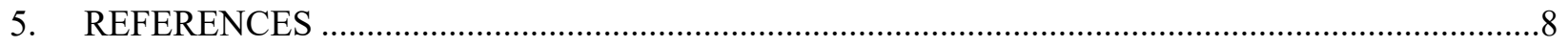




\section{FIGURES}

Figure 1. A schematic illustrating how Collison nebulizers are used to generate aerosol streams. ..............3

Figure 2. Cascade impactor stages in preparation with glass fiber filters.................................................

Figure 3. Cascade impactor used to measure particle size distribution connected to the outlet of a single jet Collison nebulizer.

Figure 4. Particle size distribution of the single jet Collison nebulizer as the argon pressure is varied......

Figure 5. The behavior of (a) the mean particle diameter, (b) the flow rate of liquid out of nebulizer, (c) the $342.2 \mathrm{~nm} \mathrm{Gd(II)} \mathrm{peak} \mathrm{area,} \mathrm{and} \mathrm{(d)} \mathrm{the} \mathrm{plasma} \mathrm{electron} \mathrm{density} \mathrm{as} \mathrm{the}$ nebulizer pressure is varied. 


\section{EXECUTIVE SUMMARY}

Measuring the aerosol evolution from MSRs is important for monitoring the off-gas system of the reactor and is particularly important for detecting off-normal conditions. In a molten salt reactor (MSR) accident scenario, an aerosol release would be a major factor in the source term. This aerosol stream would likely be generated from a breach in the cover gas system, which causes particles produced from fission itself to escape, or from a salt spill that produces aerosols through splashing and secondary reactions. The particle size of the produced aerosols is anticipated to vary greatly and range from 0.01 to $10 \mu \mathrm{m}$. The transport of these aerosols would be dependent on the particle size. A better understanding of aerosol generation, size, and monitoring methods are needed to inform estimation and mitigation of potential aerosolized source terms from MSRs. While salt spill experiments are being performed at Argonne National Laboratory, the development of aerosol characterization and monitoring methods are being developed at Oak Ridge National Laboratory. To generate prototypic aerosols for use in testing monitoring instruments and mitigation methods, a surrogate aerosol stream was produced with a Collison nebulizer, and the particle size distributions were measured with a cascade impactor. The results demonstrated that by changing the nebulizer pressure, the aerosol particle size distribution can be adjusted to best match the region of interest for experiments with higher pressures, driving the particle size down. However, nearly all aerosols formed exceeded $1 \mu \mathrm{m}$ in diameter, providing a lower bound for the surrogate aerosol stream. In addition to verifying the applicability of this surrogate aerosol stream, this work has shown that a laser induced breakdown spectroscopy monitoring system that is under development is resilient to changes in particle sizes, increasing its robustness for off-gas monitoring.

\section{INTRODUCTION}

Aerosol release is being considered as a contributor to the source term in the event of a reactor accident. Possible events that could lead to aerosol release include a breach of the cover gas system for a salt-fueled MSR or a salt spill from the primary circuit. In both cases, the breach would allow airborne species to escape from the reactor core, although the mechanisms leading to the breach events are quite different.

The cover gas of a salt-fueled MSR leaving the reactor core is expected to contain both noble and nonnoble gases, aerosols, volatile species, tritium, radionuclides, and their decay daughters. Particulates from structural materials, salt mists, and aerosols from condensed noble gas decay daughters could be generated in several ways during reactor operation. Mists and aerosols can be generated by the fuel salt through splashing, volatilization, radioactive recoil near the surface, or the migration of undissolved noble metal clusters from the surface of the salt [1]. During the Molten Salt Reactor Experiment (MSRE) operation, it was estimated that $<1 \mathrm{~mol} \%$ of the salt became airborne, which did contain some noble metals, although the main constituents of this airborne fraction consisted of salts containing daughters of $\mathrm{Kr}$ and $\mathrm{Xe}$ (i.e., $\mathrm{Cs}, \mathrm{Ce}, \mathrm{Ba}, \mathrm{Rb}, \mathrm{Sr}, \mathrm{Y}$ ), Ba, as well as I as a fission product and from the decay of Te, $\mathrm{Br}$, and Se [2]. This is the primary way that salt-soluble fission and activation products will enter the off-gas system.

The nonvolatile components in the off-gas stream for the reference molten salt breeder reactor (MSBR) were described as being mists or smokes (particles) at relatively low concentration (probably between 100 and 1,000 ppm by volume) divided into three groups [3]:

1. Fuel salt particles, generated in the pump bowl and the bubble separator, having potential sizes ranging from 1 to $10 \mu \mathrm{m}$. 
2. An estimated $1-50 \%$ of all the noble metal ( $\mathrm{Nb}$ through $\mathrm{Te}$ ) fission products were entrained in particles ranging in size from 0.01 to $10 \mu \mathrm{m}$. For a 2,250 MW(t) reactor, the mass flow rate could be as high as $300 \mathrm{~g} /$ day.

3. Nonvolatile fission product decay daughters of $\mathrm{Kr}$ and $\mathrm{Xe}$. Noble gas daughters, which are born in the salt, are assumed to be retained in the salt as fluorides. For a 2,200 MW(t) reactor, and assuming a 2 hour gas holdup volume, an estimated $140 \mathrm{~g}$ /day of noble gas daughters will accumulate in the holdup tank. Many of these will likely deposit on the walls of the tank, but their chemical form is not definitively known.

During normal operation, the cover gas is maintained to remove airborne radionuclides, including aerosols. The main driver for removing the particulates, mists, and aerosols is to prevent plugging of the cover gas piping in filters located after the decay tank. In the MSRE, pressurized He (1.3 bar) was used to sparge the salt and push fission gases toward a series of metal filters and charcoal beds, which were then vented to the atmosphere $[2,4]$. The system did not work well because it was prone to plugging. Many of the plugging issues were the result of carbon deposits in the system, mostly from pump oil pyrolysis; however, this is not typical of modern MSRs. Both solid sorbents [5-9] and liquid scrubbing methods [10] have been proposed for removal of aerosols including mists, splashes, particulates, and the condensed daughters of fission gases. Additionally, some of these products will also plate out throughout the system and accumulate over time.

In the case of a hypothetical salt spill event, the primary circuit is breached in a location that does not provide the standard off-gas treatment components. In one scenario, the salt could flow through a crack in the reactor cooling system and pool on a floor inside the primary containment area. As the fission gases are released from the salt, they will decay, and fumes will form from secondary aerosols. The salt may freeze into mists, and these also will deposit inside containment. The speciation of the aerosols will be similar to an off-gas breach, but the surface area of the salt may be much larger, causing a greater instant release fraction. Depending on the location of the breach, the salt may penetrate into the secondary loop. A pipe break would provide a more violent spill than a trickle through a crack, that might freeze shut. Research at Argonne National Laboratory is underway to characterize aerosols from a salt spill experiment. The work described here is complementary to the Argonne work, as the focus is more on a breach in the off-gas and the aerosol transport that could contribute to the source term. In the future, commonalities and differences in identified aerosol transport mechanisms will be explored to reduce uncertainties in severe accident consequence analyses.

\section{EXPERIMENTAL}

The aerosol stream used as a surrogate off-gas in this study was generated using a Collison nebulizer. A Collison nebulizer forces the carrier gas through a small aperture, which then siphons liquid from a reservoir and jets the gas out into the body of the nebulizer [11,12]. Large liquid particles will impact the wall and return to the reservoir, but finer particles will remain in suspension and form the transported aerosol stream. For future molten salt aerosol experiments, this functionality will mitigate clogging issues unlike in traditional concentric nebulizers, which force the liquid through a small opening [12]. A schematic of a single jet Collison nebulizer is shown in Figure 1 [12]. 


\section{Nebulizer tip}

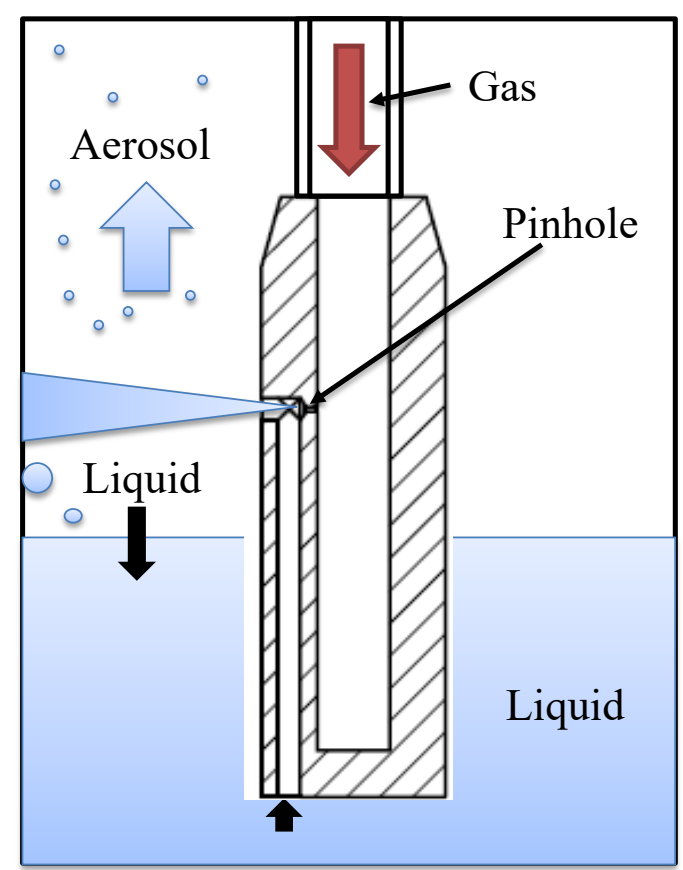

Figure 1. A schematic illustrating how Collison nebulizers are used to generate aerosol streams. Illustration reproduced courtesy of A. N.Williams [12].

The produced aerosol stream was passed into a Marple series 290 cascade impactor to measure the particle size distribution. Cascade impactors are composed of a series of stages with varying slot opening sizes. An aerosol stream is passed through the impactor, and if a particular aerosol particle aerodynamic diameter is greater than the stage's cut-off diameter then it will impact the stage. If the aerosol particle is less than the cut-off diameter, it will pass onto the next stage and the process repeats $[13,14]$. This is analogous to sieving powders. Each stage is equipped with a filter to capture and retain particles that impact the filter. The cascade impactor and stages can be seen in Figure 2. These filters are weighed before and after flowing an aerosol stream through the device to calculate the particle size distribution. A picture of the complete experimental setup including the Collison nebulizer and cascade impactor is shown in Figure 3. 


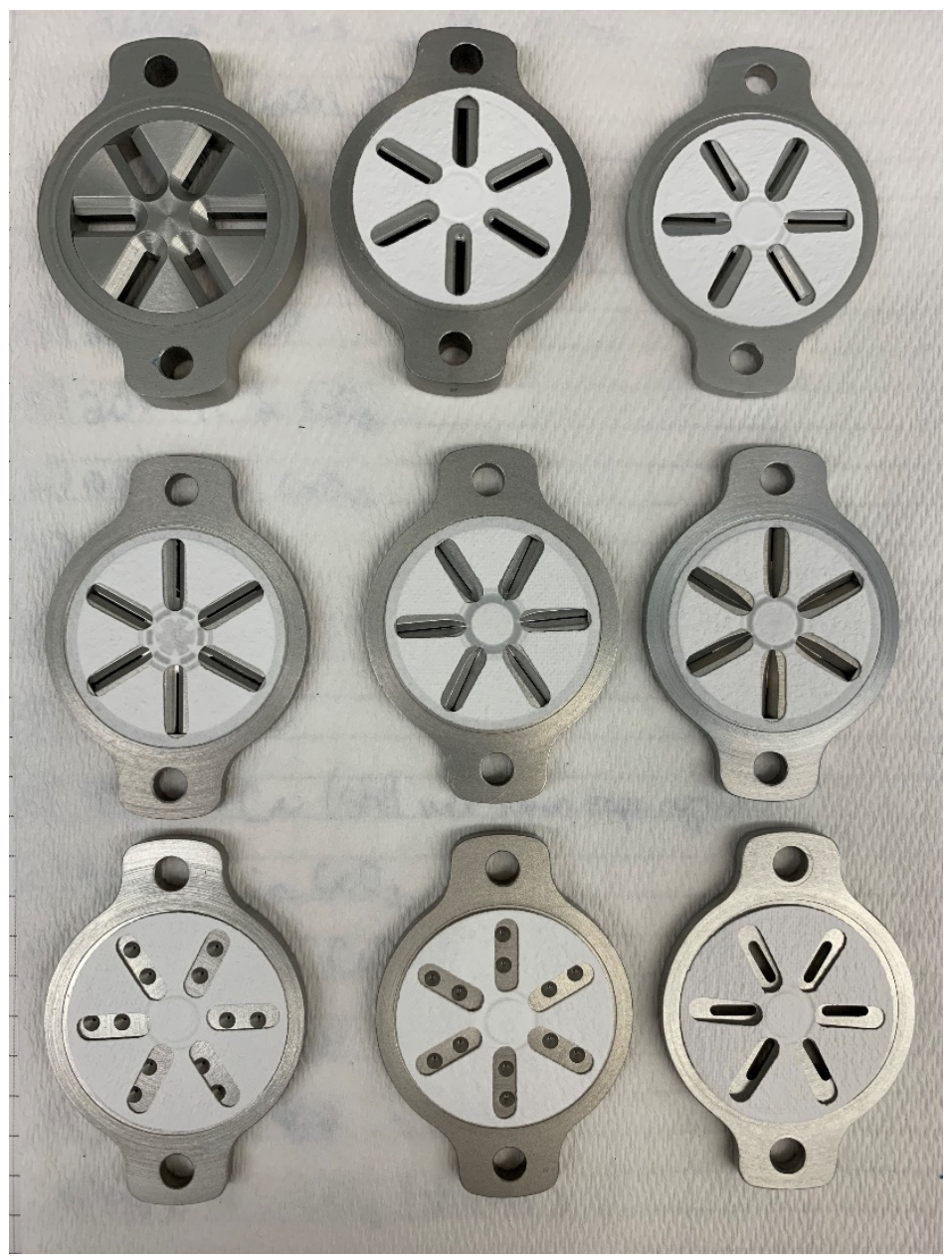

Figure 2. Cascade impactor stages in preparation with glass fiber filters. The stages are laid in sequential order from left to right, top to bottom. 


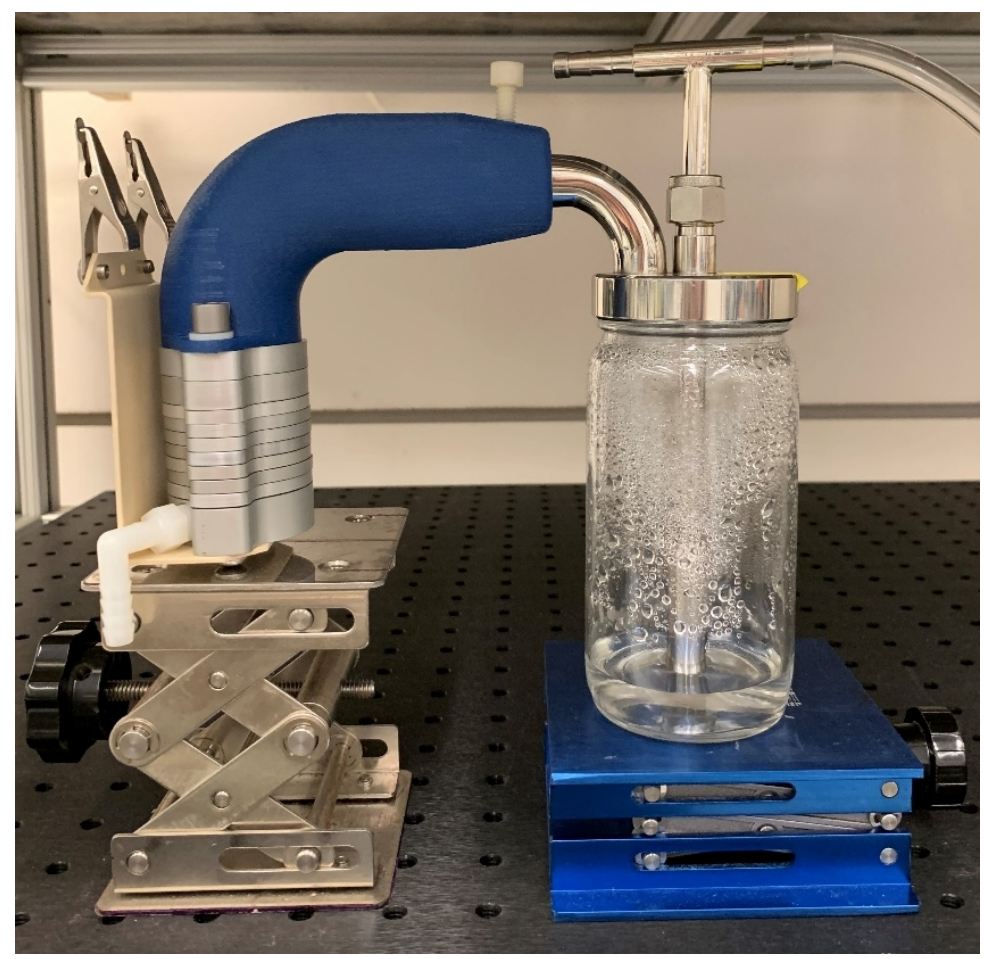

Figure 3. Cascade impactor used to measure particle size distribution connected to the outlet of a single jet Collison nebulizer.

Aerosols were produced from samples of deionized water $(17.6 \mathrm{M} \Omega \cdot \mathrm{cm})$ spiked with different lanthanide ICP standards (Inorganic Ventures ICP standards). The particle size distribution was measured at various nebulizer pressures ranging from 5 to 40 psig (1.3-3.8 bar). In addition to measuring the particle size distribution, laser induced breakdown spectroscopy (LIBS) measurements were performed at each pressure to better understand the impact of particle sizing on spectral response. A LIBS device for monitoring aerosols and gases in an MSR off-gas system is under development, thus understanding the impact of aerosol properties is vital. For this an Applied Photonics LIBSCAN 150 system was used with a Catalina Scientific Instruments EMU-120/65 spectrometer. This Nd:YAG laser was operated at 1,064 nm and $160 \mathrm{~mJ}$ per shot, using a $1 \mathrm{~Hz}$ shot frequency. The spectra were collected with a gate delay of $5 \mu \mathrm{s}$ and a gate width of $15 \mu \mathrm{s}$. Spectra were averaged over 20 shots and normalized to the argon intensity to account for laser energy variation.

\section{RESULTS AND DISCUSSION}

The particle size distribution was measured from the Collison nebulizer operated at pressures ranging from 5 to 40 psig. The 5 psig pressure did not produce an adequate aerosol stream and is not included in the remaining analysis. Figure 4 is a log-normal probability plot that shows changes in the cumulative particle size distribution as the operating pressure is increased. This figure illustrates that increasing the pressure drives the particle size distribution toward smaller diameter particles, but there are diminishing effects beyond $30 \mathrm{psig}$. Interestingly, the particle size is almost always greater than $1 \mu \mathrm{m}$ despite the operating pressure, which is a good indication that the Collison nebulizer can produce a surrogate aerosol stream that properly represents what might be produced from an MSR because the majority of the salt aerosols during the MSRE were estimated to be greater than $1 \mu \mathrm{m}[3]$. 


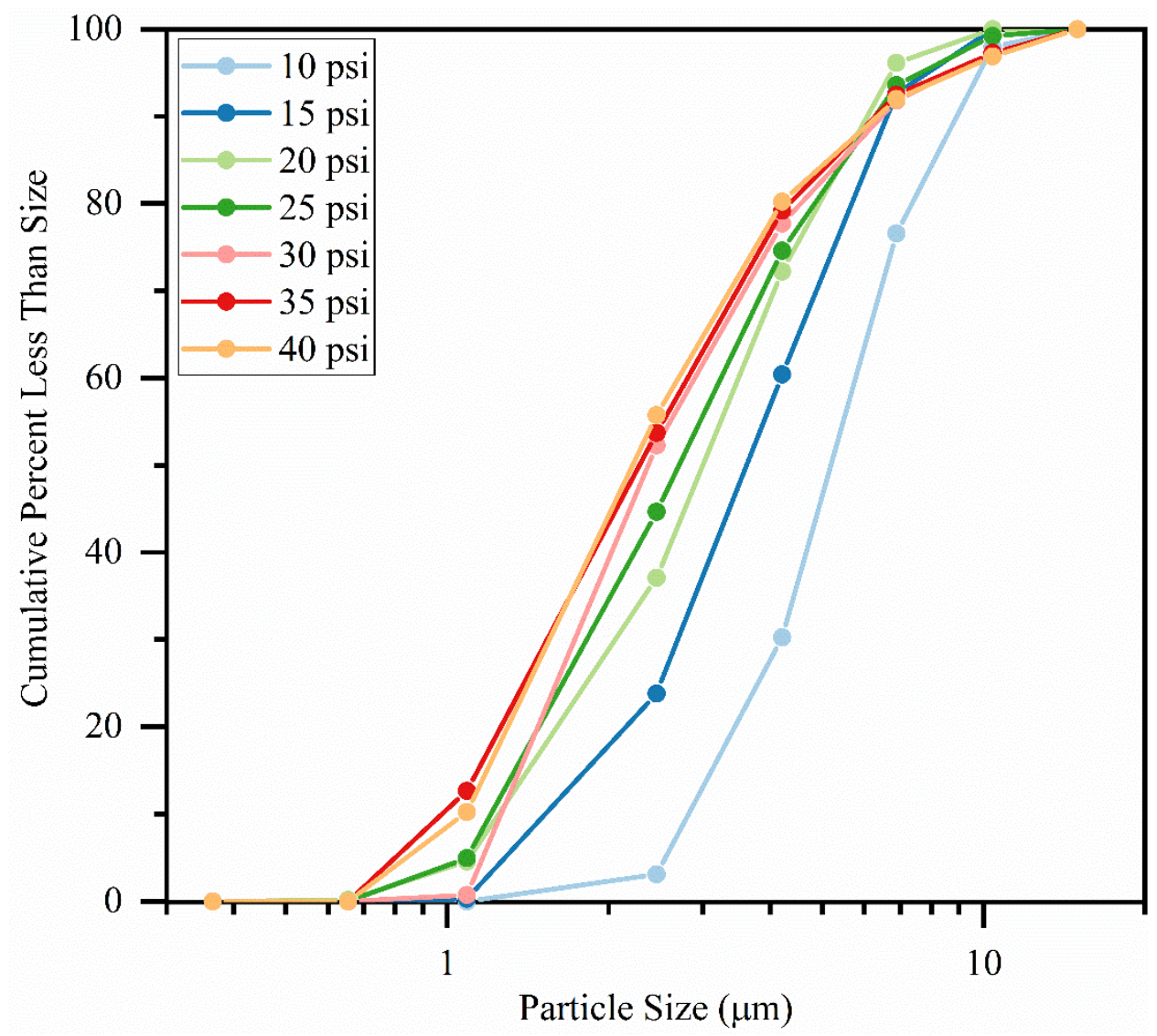

Figure 4. Particle size distribution of the single jet Collison nebulizer as the argon pressure is varied.

The mean particle diameter for each pressure can be determined from Figure 4 by identifying the point on each line that corresponds to a $50 \%$ probability [15]. The particle size geometric standard deviation is calculated as the square root of the ratio between the $84.13 \%$ diameter and the $15.87 \%$ diameter $\left(\sigma_{\mathrm{g}}=\operatorname{sqrt}\left(\mathrm{D}_{84.13 \%} / \mathrm{D}_{15.87 \%}\right)\right)[16]$. The mean particle diameter decreases as the pressure is increased, but the standard deviation of the distribution increases slightly. Both values are provided in Table 1.

Table 1. Mean particle diameter as the nebulizer pressure is varied.

\begin{tabular}{lccccccc}
\hline \multicolumn{1}{c}{ Pressure $(\mathbf{p s i})$} & $\mathbf{1 0}$ & $\mathbf{1 5}$ & $\mathbf{2 0}$ & $\mathbf{2 5}$ & $\mathbf{3 0}$ & $\mathbf{3 5}$ & $\mathbf{4 0}$ \\
\hline Mean diameter $(\mu \mathrm{m})$ & 5.35 & 3.71 & 3.10 & 2.77 & 2.40 & 2.33 & 2.29 \\
Standard deviation $(\mu \mathrm{m})$ & 1.57 & 1.76 & 1.88 & 1.95 & 1.91 & 2.09 & 2.01 \\
\hline
\end{tabular}

The variation in mean particle diameter versus nebulizer pressure is shown graphically in Figure 5(a). Several additional parameters were investigated as a function of pressure. Each cascade impactor measurement was performed over a recorded time interval, which allowed the flow rate of liquid in the nebulizer reservoir being converted into an aerosol to be calculated, shown in Figure 5(b). As expected, this increases with an increase in pressure, but its measurement allows for the concentration of species in the aerosol stream to be calculated from the known concentration in the liquid reservoir.

The LIBS spectra were collected with a sample containing dissolved Gd, Nd, and Sm. The normalized peak areas were measured as the pressure was changed to infer any effects of particle sizing on the 
measurements. All the analytes had a similar response, and the $342.2 \mathrm{~nm}$ Gd II peak area versus nebulizer pressure is shown in Figure 5(c). The optimal pressure for the LIBS system was determined to be 20 psig (2.4 bar), but there is truly little difference at any pressures above $15 \mathrm{psig}(2.1 \mathrm{bar})$. The variation in signal above 20 psig is likely due to noise rather than the aerosol properties. This can be interpreted to mean that the LIBS plasma consumes aerosol particles over a range of sizes, and the benefit of pressures greater than 15 psig is meeting a threshold flow rate such that each shot consumes an adequate number of particles. One concern about performing LIBS on flowing systems is that the produced plasma might be quickly quenched by incoming aerosol particles, reducing its effective lifetime. The electron density was measured using the full width at half maximum of the $656.28 \mathrm{~nm} \mathrm{H}_{\alpha}$ peak [17]. This density was found to be unaffected by nebulizer pressure as shown in Figure 5(d). Furthermore, it is on the level expected of a laser induced plasma $\left(\sim 10^{17} \mathrm{~cm}^{-3}\right)[17]$.
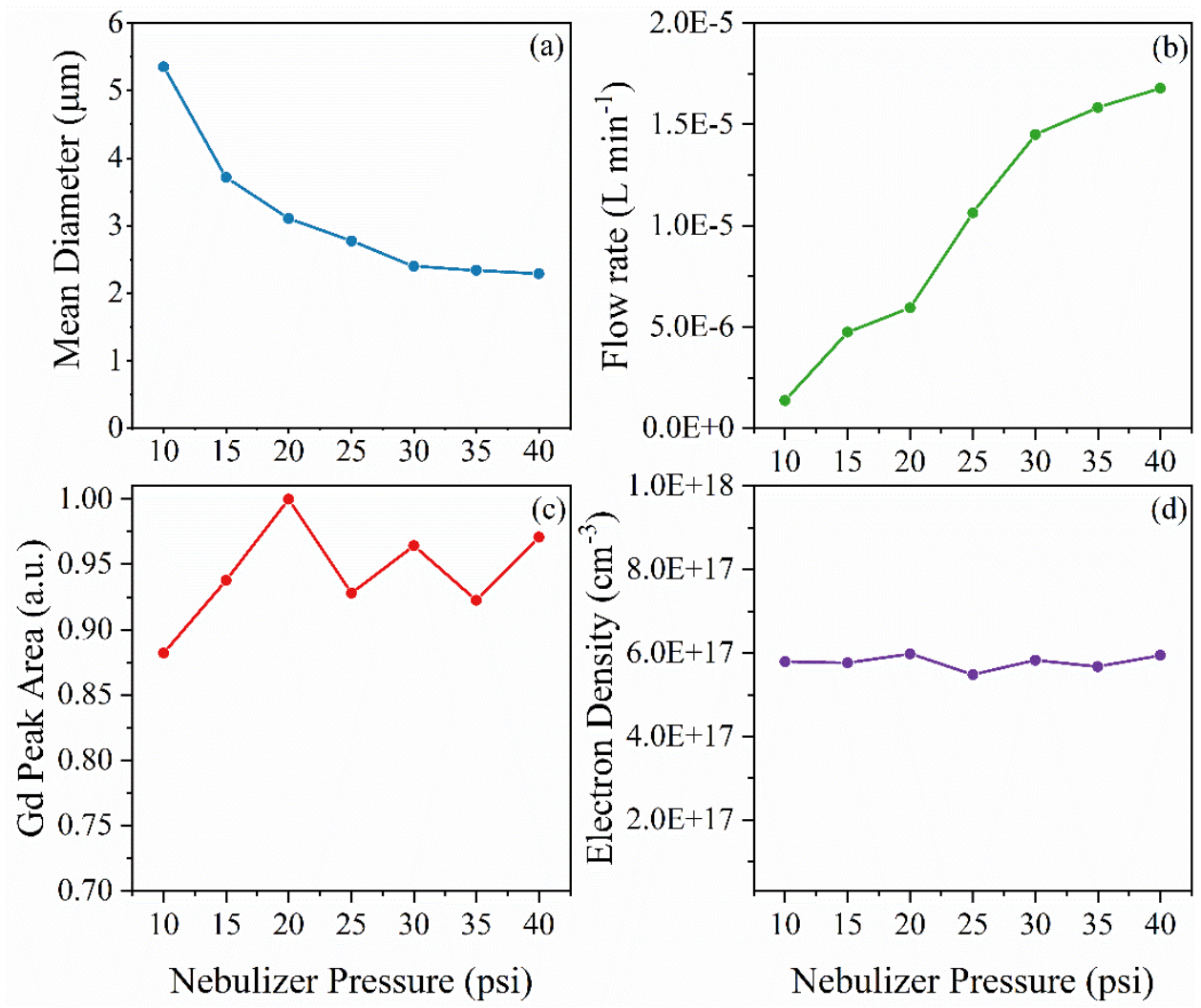

Figure 5. The behavior of (a) the mean particle diameter, (b) the flow rate of liquid out of nebulizer, (c) the $342.2 \mathrm{~nm}$ Gd II peak area, and (d) the plasma electron density as the nebulizer pressure is varied.

\section{CONCLUSION}

This study has several key takeaways. First, the LIBS sensor under development is capable of monitoring elemental signals over a range of aerosol particle sizes. This makes the system more robust in application, as it should be applicable to the particle sizes anticipated from an MSR-produced aerosol stream [3]. Secondly, the Collison nebulizer can be used to produce surrogate aerosol streams with particle size distributions matched to those anticipated from an MSR. Lastly, the methodology for aerosol particle size measurement has successfully been demonstrated using an aqueous system. Future work will apply these methods to a molten salt aerosol test stand that is under development, as well as to the salt spill experiments being performed at Argonne National Laboratory. 


\section{REFERENCES}

1. Engel, J. R., P. N. Haubenreich, A. Houtzeel, 1970, Spray, Mist, Bubbles, and Foam in the Molten Salt Reactor Experiment, ORNL-3027, Oak Ridge National Laboratory, Oak Ridge, TN.

2. Compere, E. L., S. S. Kirslis, E. G. Bohlmann, F. F. Blankenship, and W. R. Grimes. 1975. Fission Product Behavior in the Molten Salt Reactor Experiment. ORNL-4865, Oak Ridge National Laboratory, Oak Ridge, TN.

3. McNeese, L. E. 1974. Program Plan for the Development of Molten-Salt Breeder Reactors. ORNL5018, Oak Ridge National Laboratory, Oak Ridge, TN.

4. Thoma, R. E. 1971. Molten-Salt Reactor Program. ORNL-4658, Oak Ridge National Laboratory, Oak Ridge, TN.

5. Smith, G. P. 1956. Corrosion of Materials in Fused Hydroxides. ORNL-2048, Oak Ridge National Laboratory, Oak Ridge, TN.

6. Greenwood, M. S., B. Betzler, and A. L. Qualls. 2018. Dynamic System Models for Informing Licensing and Safeguards Investigations of Molten Salt Reactors. ORNL/TM-2018/876, Oak Ridge National Laboratory, Oak Ridge, TN.

7. Zagnit'ko, A. V., and Y. D. Chuvilin. 2009. "Nanoaerosols Formation during the Bubbling of Lithium and Beryllium Fluorides Molten Salt to Produce Reactor Radioisotopes." Nanotechnologies in Russia 4(11-12): 851-856.

8. Robertson, R. C. E. 1971. Conceptual Design Study of a Single-Fluid Molten-Salt Breeder Reactor. ORNL-4541, Oak Ridge National Laboratory, Oak Ridge, TN.

9. International Atomic Energy Agency. 1987. Design of Off-Gas and Air Cleaning Systems at Nuclear Power Plants. IAEA-Technical Reports No. 274. International Atomic Energy Agency, Vienna, Austria.

10. Vienna, J. D., E. D. Collins, J. V. Crum, W. L. Ebert, S. M. Frank, T. G. Garn, D. Gombert, R. Jones, R. T. Jubin, V. C. Maio, J. C. Marra, J. Matyas, T. M. Nenoff, B. J. Riley, G. J. Sevigny, N. R. Soelberg, D. M. Strachan, P. K. Thallapally, and J. H. Westsik. 2015. Closed Fuel Cycle Waste Treatment Strategy. FCRD-MRWFD-2015-000674, PNNL-24114, Pacific Northwest National Laboratory, Richland, WA.

11. May, K. R. 1973. “The Collison Nebulizer: Description, Performance and Application.” J. Aerosol Sci. 4(3): 235-243.

12. Williams, A. N. 2016. "Measurement of Rare Earth and Uranium Elements Using Laser-Induced Breakdown Spectroscopy (LIBS) in an Aerosol System for Nuclear Safeguards Applications." Doctoral dissertation. Virginia Commonwealth University, Richmond, VA.

13. Marple, V. A., K. Willeke, 1976, “Impactor Design,” Atmospheric Environment, 10(10), 891-896.

14. Newton, G. J., O. G. Raabe, B. V. Mokler. 1977. “Cascade Impactor Design and Performance,” J. Aerosol Sci. 8(5): 339-347. 
15. NIST/SEMATECH. 2021. e-Handbook of Statistical Methods. Available:

http://www.itl.nist.gov/div898/handbook/.

16. Johnson, N. L., S. Kotz, and N. Balakrishnan, Continuous Univariate Distributions. Vol. 1. Second edition. Wiley Series in Probability and Mathematical Statistics: Applied Probability and Statistics.. John Wiley \& Sons, New York, 1994.

17. Farooq, Z., R. Ali, U. S. Qurashi, M., H. R. Mahmood, M. Yaseen, M. A. Qayyum, M. N. Hussain, S. M. Shah, and T. Jan. 2018. "Spectroscopic Studies of Laser Produced Plasma of Doped Nanostructured Material by Laser Induced Breakdown Spectroscopy,” Physics of Plasmas 25. 


(n)

